\title{
Women with Fear of Childbirth Perceived Large Accumulated Labor Pain in Japan
}

\author{
Yukie Iizuka $^{1}$, Naoki Masaoka ${ }^{2}$, Kazutomo Ohashi ${ }^{1}$ \\ ${ }^{1}$ Division of Health Sciences, Graduate School of Medicine, Osaka University, Suita, Japan \\ ${ }^{2}$ Department of Maternal and Fetal Medicine, Yachiyo Medical Center, Tokyo Women's Medical University, Tokyo, Japan \\ Email: yukieiizuka@sahs.med.osaka-u.ac.jp,masaoka.naoki@twmu.ac.jp, ohashi@sahs.med.osaka-u.ac.jp
}

How to cite this paper: Iizuka, Y., Masaoka, N. and Ohashi, K. (2018) Women with Fear of Childbirth Perceived Large Accumulated Labor Pain in Japan Open Journal of Nursing, 8, 656-668.

https://doi.org/10.4236/ojn.2018.89049

Received: August 17, 2018

Accepted: September 18, 2018

Published: September 21, 2018

Copyright $\odot 2018$ by authors and Scientific Research Publishing Inc. This work is licensed under the Creative Commons Attribution International License (CC BY 4.0).

http://creativecommons.org/licenses/by/4.0/

\begin{abstract}
Background: To improve negative birth experiences among women who experience intense labor pain during labor, it is important to examine the relationship between fear of childbirth immediately after vaginal delivery and the actual intensity of labor pain. However, previous studies have generally evaluated labor pain in a retrospective setting. Purpose: This study examined the relationship between fear of childbirth immediately after vaginal delivery and the actual labor pain intensity and accumulated labor pain intensity without pharmacological pain relief during labor in Japan. Methods: A prospective observational study was conducted between July 2015 and April 2016. Forty-seven pregnant Japanese women were available for analysis. Fear of childbirth was measured by the Japanese version of the Wijma Delivery Expectancy/Experience Questionnaire (JW-DEQ) version B on the third day after vaginal delivery. Participants with scores of 85 or higher were categorized in the high JW-DEQ group, having severe fear of childbirth. Labor pain intensity was examined chronologically in real time with stepwise usage of two types of Numeric Rating Scale (NRS). Accumulated labor pain intensity was calculated using the area under the curve (AUC). Results: Nine participants were in the high JW-DEQ group and eight of the nine were primiparae. Primiparae in the high JW-DEQ group experienced significantly longer duration and larger accumulated labor pain intensity between the onset of labor and 4 to $6 \mathrm{~cm}$ of cervical dilatation than those in the low JW-DEQ group $(P=0.024$ and $P=$ 0.021, respectively). Conclusions/Implications for Practice: The latent phase of labor was a key stage to improve fear of childbirth immediately after vaginal delivery without pharmacological pain relief among Japanese primiparae. Midwives should give assistance in the latent phase of labor by focusing on progressing labor smoothly and relieving labor pain to improve negative birth experiences.
\end{abstract}




\section{Keywords}

Accumulated Labor Pain Intensity, Area under the Curve, Fear of Childbirth, Labor Pain Intensity, Vaginal Delivery

\section{Introduction}

Fear of childbirth is a negative emotion and can be divided into two forms: anticipatory fear during pregnancy and experienced fear after delivery [1]. One of the key components of fear of childbirth is considered to be fear of pain [2]. Fear of childbirth after delivery was correlated with labor pain estimated retrospectively 2 days after delivery among Japanese primiparae [3]. Women preferred a cesarean section in subsequent pregnancies due to fear of pain [4]. Women with severe fear of childbirth during pregnancy had increased incidence of elective cesarean section [5] [6]. Moreover, severe labor pain and fear of childbirth both during pregnancy and after delivery led to negative birth experiences [7] [8], and negative birth experiences recalled 2 days after delivery did not improve for up to 9 months [7]. However, previous studies examining the relationship between fear of childbirth after delivery and labor pain have generally measured labor pain retrospectively.

To assess labor pain appropriately, it is important to measure the pain intensity in real time during labor. The intensity of labor pain examined retrospectively differed significantly from the pain that was actually experienced [9]. However, in the previous study, intensity of labor pain was evaluated only 3 times and included participants receiving pharmacological pain relief during labor [9]. Additionally, the duration is also important in managing pain because the pain changes over time. Therefore, the area under the curve (AUC) produced by actual intensity of pain and its duration should be used as an indicator of overall pain burden [10].

There were 976,978 live births in Japan in 2016 [11]. About 80 percent of the childbirths were vaginal deliveries [12], and most vaginal deliveries did not use obstetrical analgesia or anesthesia during labor. Therefore, most pregnant Japanese women experience intense labor pain when giving birth. In countries like Japan where vaginal delivery without pharmacological pain relief is mainly provided, it is important to examine the relationship between fear of childbirth immediately after vaginal delivery and the actual intensity of labor pain to improve negative birth experiences among women who experience pain throughout labor.

In this study, we evaluated the actual intensity of labor pain chronologically in real time and calculated the AUC produced by the intensity of labor pain and duration of labor as an indicator of accumulated labor pain intensity. We also identified the association between fear of childbirth immediately after vaginal delivery and the actual intensity of labor pain at two points (at 4 to $6 \mathrm{~cm}$ of cervical dilatation and at full cervical dilatation) and the accumulated labor pain 
intensity.

\section{Methods}

\subsection{Participants and Setting}

A prospective observational study was conducted between July 2015 and April 2016 at two private clinics and one university hospital in Tokyo and Chiba Prefectures. Chiba Prefecture is located to the east of Tokyo. The inclusion criteria of the participant were Japanese women with a singleton pregnancy at 37 to 41 weeks of gestation. We excluded the following women from the study: unmarried, less than 20 years old, having a past medical history of cesarean section or instrumental delivery, having a past history of stillbirth or an injured newborn, and having complications requiring medication at the start of this research. Sixty-one women agreed to participate and 13 were excluded because of emergency caesarean section during the study (4 cases), rapid progress of labor (2 cases), prolonged labor (2 cases) and more than $6.0 \mathrm{~cm}$ of cervical dilatation at the start of research (5 cases). One woman was excluded due to neonatal asphyxia. Ultimately, 47 women analyzed in this study.

This study was approved by the Ethics Committees of Health Sciences, Osaka University (No. 321) and of Tokyo Women's Medical University (No. 3429). All participants received a detailed explanation and completed a written informed consent form in which the anonymity, confidentiality and right of withdrawal at any time from the study were assured. This study gave priority to clinical practices when measuring during labor and on the third day after delivery.

\subsection{Measurements}

\subsubsection{Fear of Childbirth (Experience)}

Fear of childbirth (experience) immediately after vaginal delivery was measured by the Japanese version of the Wijma Delivery Expectancy/Experience Questionnaire (JW-DEQ) version B on the third day after delivery [13]. The W-DEQ was originally developed in Sweden and is used to measure the level of fear related to childbirth during pregnancy (expectancy) in version A and that after delivery (experience) in version B [1]. The Cronbach's alpha value of the original Swedish version B was 0.93 at 2 hours after delivery and 0.94 at 5 weeks postpartum [1]. The JW-DEQ versions A and B examine four factors: fear, lack of positive anticipation, isolation and riskiness [13] [14], and are consistent with the Swedish and English versions [15] [16]. The Cronbach's alpha value of JW-DEQ version B was 0.94 on the second day after delivery [13]. The scale consists of 33 items with six-point responses, ranging from "not at all" (0) to "extremely" (5). The total score ranges from 0 to 165 and higher scores indicate a higher level of fear of childbirth. Scores over 85 indicate a severe fear of childbirth.

\subsubsection{Labor Pain Intensity}

Labor pain intensity was evaluated by the Numeric Rating Scale (NRS) chrono- 
logically in real time. The NRS is widely utilized in several clinical practices and studies as an assessment tool of labor pain similar to the Visual Analog Scale (VAS). The NRS has an eleven-point numeric scale and has been shown to be applicable for unidimensional assessment of pain intensity because of higher compliance rates, better responsiveness, ease of use, and better applicability relative to VAS [17]. Participants choose a segmented number to indicate their pain intensity at that moment [18].

In this study, the labor pain intensity was evaluated by stepwise usage of two types of NRS. The NRS-10 estimates pain intensity as a score of 0 (no pain) to 10 (the worst pain imaginable) on a $100 \mathrm{~mm}$ line. The NRS-20 has another scale in which 10 points are added to the NRS- 10 on a $200 \mathrm{~mm}$ line, and 11 to 20 mean pain that is worse than "the worst pain imaginable". When participants scored 11 to 20 in the NRS-20, they felt worse pain than "the worst pain imaginable" in the NRS-10. It was pointed out that the scale with an upper limit of 10 had a limitation in continuously rating labor pain intensity during labor because women perceived 10 out of 10 during labor and then experienced worse pain as labor progressed. Therefore, the need for an expanded scale was suggested for assessing severer labor pain intensity [19]. In our preliminary study, we only used the NRS-10 to evaluate the labor pain intensity of women who did not receive any obstetrical analgesia or anesthesia in the time period without uterine contractions approximately every hour and sometimes found that their NRS-10 scores reached 10 during labor. Therefore, we initially used the NRS-10, and when a participant's score reached 10, we used the NRS-20 starting with the next examination. Vaginal examinations were conducted by obstetricians and midwives in the usual clinical setting. Seven participants (14.9\%) did not answer between one and five times during their labor. In these cases, we used the previous scores instead of a new score. When we could not measure the score just before delivery, we evaluated labor pain intensity immediately after delivery.

\subsubsection{Duration of Labor}

We defined the duration between the onset of labor and 4 to $6 \mathrm{~cm}$ of cervical dilatation as Stage 1-1, that between 4 to $6 \mathrm{~cm}$ of cervical dilatation and full cervical dilatation as Stage 1-2, and that between full cervical dilatation and delivery as Stage 2. The durations were calculated from data on the medical records and programs.

\subsubsection{Accumulated Labor Pain Intensity}

The accumulated labor pain intensity was calculated using pain intensity and duration as an area under the curve (AUC) by using the trapezoid rule [10] [20] [21] [22]. In this study, the AUC was separated into triangles and trapezoids as illustrated in Figure 1. AUC of Stage 1-1 represents the duration between the onset of labor and 4 to $6 \mathrm{~cm}$ of cervical dilatation. AUC of Stage 1-2 represents the duration between 4 to $6 \mathrm{~cm}$ of cervical dilatation and full cervical dilatation. AUC of Stage 2 represents the duration between full cervical dilatation 


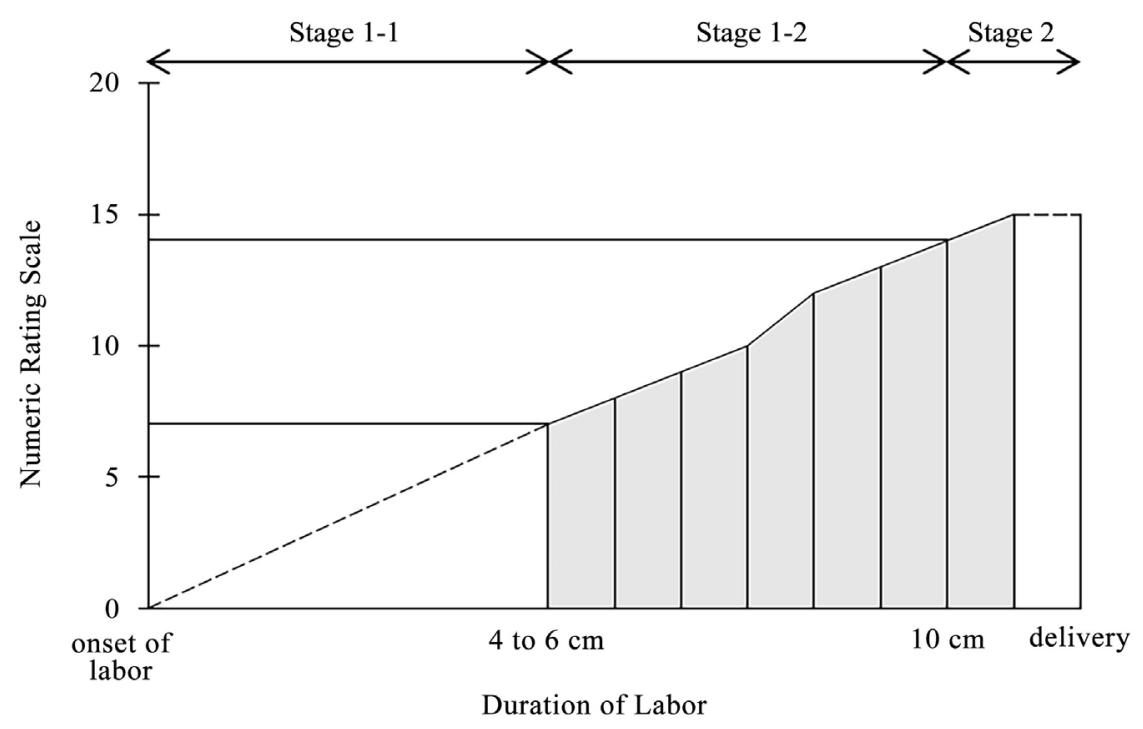

Figure 1. Area under the Curve (AUC) with Numeric Rating Scale (NRS) for labor pain intensity and duration of labor.

and delivery. AUC is divided into calculated AUC (filled) and estimated AUC. Broken lines connect estimated scores to measured scores and solid lines connect two measured scores.

Assuming that the labor pain intensity at the onset of labor was 0 and that pain during Stage 1-1 increased linearly, AUC of Stage 1-1 was estimated as the area of a triangle using the following equation:

$$
\mathrm{AUC}=\left(\mathrm{NRS}_{4 \text { to } 6 \mathrm{~cm}}\right)\left(\mathrm{Time}_{4 \text { to } 6 \mathrm{~cm}}-\text { Time }_{\text {onset of labor }}\right) / 2
$$

AUC of Stage 1-2 was calculated by measured scores as follows:

$$
\mathrm{AUC}=\sum\left(\mathrm{NRS}_{n}+\mathrm{NRS}_{n-1}\right)\left(\text { Time }_{n}-\text { Time }_{n-1}\right) / 2
$$

AUC of Stage 2 was calculated by measured scores and estimated assuming that the labor pain intensity at delivery was the same as the score before delivery as shown in the last rectangle. AUC of Stage 2 was then estimated using the following equation:

$$
\begin{aligned}
\mathrm{AUC}= & \sum\left(\mathrm{NRS}_{n}+\mathrm{NRS}_{n-1}\right)\left(\text { Time }_{n}-\text { Time }_{n-1}\right) / 2 \\
& +\left(\mathrm{NRS}_{\text {previous before delivery }}\right)\left(\text { Time }_{\text {delivery }}-\text { Time }_{\text {previous before delivery }}\right)
\end{aligned}
$$

\subsubsection{Demographic and Medical Characteristics of Participants}

The recorded maternal demographic and medical characteristics were as follows: maternal age, parity, smoking status, antenatal education, mode of delivery, induction of labor and episiotomy. As for the neonate, the birth weight and Apgar score at 5 minutes after birth were also recorded.

\subsection{Data Analysis}

The statistical analysis was performed with IBM SPSS Statistics 23.0 (SPSS Inc., Chicago, Illinois). All statistical tests were two tailed, and $P$-values $<0.05$ were 
considered statistically significant. To analyze the maternal age and the duration of labor of participants, the birth weight, 5-minute Apgar score and the total score of the JW-DEQ version B, descriptive statistics were used. We compared the demographic and medical characteristics of the participants between the high JW-DEQ group (JW-DEQ scores of 85 or more) and the low JW-DEQ group (JW-DEQ scores of 84 or less) using the unpaired t-test for maternal age and the chi-squared test for parity, smoking in pregnancy, antenatal education, mode of delivery, induction of labor and episiotomy. The unpaired t-test was used to examine the obstetric factors between the two groups. To clarify the effect of parity, we also compared the obstetric factors between the high JW-DEQ group and the low JW-DEQ group in primiparae using the unpaired t-test.

\section{Results}

Of 47 participants, the mean maternal age was 31.9 years $(S D=4.8)$ and 26 (55.3\%) participants were primiparae. The mean duration of labor was 9.9 hours $(S D=6.0)$. No participant received obstetrical analgesia or anesthesia during labor. As for the neonates, all were healthy with Apgar scores at 5 minutes after birth of 8 or more. The mean birth weight was $3132.6 \mathrm{~g}(S D=293.1)$. Nine (19.1\%) participants had scores of 85 or more on the JW-DEQ, indicating severe fear of childbirth.

A comparison of the demographic and medical characteristics between the low $(<85)$ and the high ( 85 or more) JW-DEQ groups is shown in Table 1 . The high JW-DEQ group was younger than the low JW-DEQ group $(P=0.002)$. Eight of the nine in the high JW-DEQ group were primiparae and there was a significant difference in parity between the two groups $(P=0.024)$. No differences were found in smoking in pregnancy, antenatal education, mode of delivery, induction of labor or episiotomy.

Obstetric factors of the two groups are shown in Table 2. Comparing the obstetric factors between the two groups, the duration of whole labor was 12.9 ( $S D$ $=3.0)$ in the high JW-DEQ group and $9.2(S D=6.3)$ in the low JW-DEQ group. The duration from the onset of labor to the time when cervical dilatation reached 4 to $6 \mathrm{~cm}$ (Stage 1-1) was $8.2(S D=3.3)$ in the high JW-DEQ group and $4.1(S D=3.5)$ in the low JW-DEQ group. The duration of whole labor and the duration from the onset of labor to the time when cervical dilatation reached 4 to $6 \mathrm{~cm}$ (Stage 1-1) in the high JW-DEQ group were significantly longer than those in the low JW-DEQ group ( $P=0.015$ and $P=0.003$, respectively). The durations between 4 to $6 \mathrm{~cm}$ of cervical dilatation and full cervical dilatation (Stage 1-2) and between full cervical dilatation and delivery (Stage 2) were not significantly different between the two groups. The NRS scores of labor pain intensity at the time of 4 to $6 \mathrm{~cm}$ of cervical dilatation were $8.6(S D=3.2)$ in the high JW-DEQ group and $5.9(S D=2.4)$ in the low JW-DEQ group. The NRS scores of labor pain intensity at the time of 4 to $6 \mathrm{~cm}$ of cervical dilatation in the high JW-DEQ group were significantly higher than those in the low JW-DEQ 
group $(P=0.007)$. The accumulated labor pain intensity in Stage $1-1$ were 31.7 $(S D=10.6)$ in the high JW-DEQ group and $13.4(S D=14.8)$ in the low JW-DEQ group. The high JW-DEQ group showed significantly higher scores of accumulated labor pain intensity in Stage $1-1$ than the low JW-DEQ group $(P=0.001)$. There were no significant differences between the two groups in the whole labor and Stages 1-2 and 2.

As described above, eight of the nine in the high JW-DEQ group were primiparae. We compared the obstetric factors between the two groups among all 26 primiparae in Table 3 . The scores of pain intensity at three measurements (at the time of 4 to $6 \mathrm{~cm}$ of cervical dilatation, at full cervical dilatation and immediately after delivery) did not differ between the high and the low JW-DEQ groups. In contrast, the duration in Stage $1-1$ was $8.6(S D=3.3)$ in the high JW-DEQ group and $4.8(S D=3.8)$ in the low JW-DEQ group. The accumulated labor pain intensity in Stage 1-1 was $33.5(S D=9.8)$ in the high JW-DEQ group and $16.7(S D=18.0)$ in the low JW-DEQ group. The duration and accumulated labor pain intensity in Stage 1-1 in the high JW-DEQ group were significantly higher than in the low JW-DEQ group ( $P=0.024$ and $P=0.021$, respectively). In the other stages, there were no significant differences in duration and accumulated labor pain intensity between the two groups.

Table 1. Comparison of demographic and medical characteristics between low and high JW-DEQ groups $(\mathrm{n}=47)$.

\begin{tabular}{cccc}
\hline Demographic and medical characteristics & $\begin{array}{c}\text { Low }(<85) \\
(\mathrm{n}=38)\end{array}$ & $\begin{array}{c}\text { High }(85 \text { or more }) \\
(\mathrm{n}=9)\end{array}$ & $P$-value \\
\hline Maternal age (years) mean (SD) & $32.9(4.5)$ & $27.6(3.7)$ & $0.002^{\star}$ \\
Parity & $18(47.4)$ & $8(88.9)$ & $0.024^{\star}$ \\
Primiparae n (\%) & $20(52.6)$ & $1(11.1)$ & \\
Multiparae n (\%) & $0(0.0)$ & $1(11.1)$ & 0.170 \\
Smoking in pregnancy n (\%) & $20(52.6)$ & $7(77.8)$ & \\
Antenatal education n (\%) & $36(94.7)$ & $9(100.0)$ & \\
$\quad$ Mode of delivery & $2(5.3)$ & $0(0.0)$ & 0.075 \\
Spontaneous vaginal n (\%) & $17(44.7)$ & $7(77.8)$ & 0.407 \\
Instrumental vaginal n (\%) & $29(76.3)$ & $8(88.9)$ & \\
Induction of labor n (\%) & & \\
Episiotomy n (\%) &
\end{tabular}

JW-DEQ: The Japanese version of the Wijma Delivery Expectancy/Experience Questionnaire. ${ }^{\star} P$-values $<$ 0.05 were considered statistically significant. Differences between the groups were compared by t-test for continuous variables and chi-squared test for categorical variables.

Table 2. Comparison of obstetric factors between low and high JW-DEQ groups $(n=47)$.

\begin{tabular}{cccc}
\hline Obstetric factors & $\begin{array}{c}\text { Low }(<85) \\
(\mathrm{n}=38)\end{array}$ & $\begin{array}{c}\text { High }(85 \text { or more }) \\
(\mathrm{n}=9)\end{array}$ & $P$-value \\
\hline Time duration (hour) & & & \\
Whole labor & $9.2(6.3)$ & $12.9(3.0)$ & $0.015^{*}$ \\
Stage 1-1 & $4.1(3.5)$ & $8.2(3.3)$ & $0.003^{\star}$ \\
\hline
\end{tabular}




\section{Continued}

\begin{tabular}{|c|c|c|c|}
\hline Stage $1-2$ & $4.4(4.8)$ & $4.0(1.1)$ & 0.729 \\
\hline Stage 2 & $0.6(1.0)$ & $0.6(0.3)$ & 0.894 \\
\hline \multicolumn{4}{|l|}{ Labor pain intensity (NRS score) } \\
\hline $\begin{array}{l}\text { At the time of } 4-6 \mathrm{~cm} \text { of } \\
\text { cervical dilatation }\end{array}$ & $5.9(2.4)$ & $8.6(3.2)$ & $0.007^{*}$ \\
\hline At full cervical dilatation & $12.1(4.1)$ & $15.2(5.1)$ & 0.058 \\
\hline Immediate after delivery & $2.9(2.8)$ & $4.1(3.4)$ & 0.271 \\
\hline \multicolumn{4}{|l|}{ Accumulated labor pain intensity } \\
\hline Whole labor & $59.6(60.5)$ & $87.2(23.1)$ & 0.188 \\
\hline Stage 1-1 & $13.4(14.8)$ & $31.7(10.6)$ & $0.001^{*}$ \\
\hline Stage 1-2 & $36.7(45.2)$ & $47.4(19.3)$ & 0.494 \\
\hline Stage 2 & $9.5(19.1)$ & $8.1(3.8)$ & 0.830 \\
\hline
\end{tabular}

Stage 1-1: from the onset of labor to the time of cervical dilatation of $4-6 \mathrm{~cm}$; Stage 1-2: from the time of cervical dilatation of $4-6 \mathrm{~cm}$ to full cervical dilation; Stage 2: from full cervical dilatation to delivery; JW-DEQ: The Japanese version of the Wijma Delivery Expectancy/Experience Questionnaire. ${ }^{\star} P$-values $<$ 0.05 were considered statistically significant. Data are presented as mean $(S D)$. Differences between the groups were tested by unpaired t-test.

Table 3. Comparison of obstetric factors between low and high JW-DEQ groups among primiparae $(n=26)$.

\begin{tabular}{|c|c|c|c|}
\hline Obstetric factors & $\begin{array}{c}\text { Low }(<85) \\
(\mathrm{n}=18)\end{array}$ & $\begin{array}{c}\text { High (85 or more) } \\
(\mathrm{n}=8)\end{array}$ & $P$-value \\
\hline \multicolumn{4}{|l|}{ Time duration (hour) } \\
\hline Whole labor & $12.8(6.9)$ & $13.1(3.2)$ & 0.879 \\
\hline Stage 1-1 & $4.8(3.8)$ & $8.6(3.3)$ & $0.024^{*}$ \\
\hline Stage 1-2 & $6.8(6.0)$ & $3.8(0.8)$ & 0.052 \\
\hline Stage 2 & $1.1(1.3)$ & $0.6(0.3)$ & 0.203 \\
\hline \multicolumn{4}{|c|}{ Labor pain intensity (NRS score) } \\
\hline $\begin{array}{l}\text { At the time of } 4-6 \mathrm{~cm} \text { of } \\
\text { cervical dilatation }\end{array}$ & $6.6(2.4)$ & $8.8(3.4)$ & 0.071 \\
\hline At full cervical dilation & $13.8(4.6)$ & $15.4(5.5)$ & 0.448 \\
\hline Immediate after delivery & $3.2(3.1)$ & $3.4(2.7)$ & 0.906 \\
\hline \multicolumn{4}{|c|}{ Accumulated labor pain intensity } \\
\hline Whole labor & $93.9(72.0)$ & $88.7(24.2)$ & 0.846 \\
\hline Stage 1-1 & $16.7(18.0)$ & $33.5(9.8)$ & $0.021^{*}$ \\
\hline Stage 1-2 & $60.0(56.2)$ & $46.3(20.4)$ & 0.514 \\
\hline Stage 2 & $17.2(25.9)$ & $8.8(3.3)$ & 0.195 \\
\hline
\end{tabular}

Stage 1-1: from the onset of labor to the time of cervical dilatation of $4-6 \mathrm{~cm}$; Stage 1-2: from the time of cervical dilatation of $4-6 \mathrm{~cm}$ to full cervical dilation; Stage 2: from full cervical dilatation to delivery. JW-DEQ: The Japanese version of the Wijma Delivery Expectancy/Experience Questionnaire. ${ }^{\star} P$-values $<$ 0.05 were considered statistically significant. Data are presented as mean $(S D)$. Differences between the groups were tested by unpaired t-test. 


\section{Discussion}

In this study, we evaluated the intensity of labor pain chronologically in real time during labor, and accumulated labor pain intensity was calculated using the area under the curve (AUC) in which labor pain intensity and duration of labor are multiplied. We also examined the association between fear of childbirth immediately after vaginal delivery and obstetric factors, i.e., duration of labor, intensity of labor pain at each measurement point and accumulated labor pain intensity. The results indicated that primiparae with severe fear of childbirth experienced a longer time from the onset of labor to the time of 4 to $6 \mathrm{~cm}$ of cervical dilatation (Stage 1-1) and suffered from greater accumulated labor pain intensity, suggesting that the latent phase is a key stage in reducing the fear of childbirth immediately after delivery for primiparae.

Nine $(19.1 \%)$ participants had scores of 85 or more on the JW-DEQ, indicating severe fear of childbirth in vaginal delivery without obstetrical analgesia and anesthesia during labor. Of these nine, eight were primiparae. The mean score of JW-DEQ version B for primiparae was higher than that of multiparae among Japanese women [3] [13]. We excluded the multiparae who had a past medical history of cesarean section or instrumental delivery because these women might have greater fear of childbirth in subsequent pregnancies than those with spontaneous vaginal delivery [23] [24]. Therefore, we examined the results of primiparae as shown in Table 3.

In our study, the intensity of labor pain at 4 to $6 \mathrm{~cm}$ of cervical dilatation was not significantly different between the high and low JW-DEQ groups $(P=$ 0.071). One previous study did not find a correlation between intensity of labor pain at 3 to $5 \mathrm{~cm}$ of cervical dilatation and fear of childbirth on the second day postpartum [25]. Women without epidural analgesia (EDA) perceived the highest level of intensity of pain at full cervical dilatation [26]. Our result was similar, indicating a higher mean score of NRS at full cervical dilatation than at 4 to $6 \mathrm{~cm}$ of cervical dilatation. Participants experienced severe labor pain with a score exceeding 10, that is, women perceived an extraordinary pain that could not be imagined. However, the intensity of labor pain at full cervical dilatation was not significantly correlated with fear of childbirth immediately after delivery $(P=$ 0.448).

The accumulated labor pain intensity of Stage 1-1 from the onset of labor to the time of 4 to $6 \mathrm{~cm}$ of cervical dilatation was significantly different between the high and the low JW-DEQ groups $(P=0.021)$. According to Friedman's curve, the time of 4 to $6 \mathrm{~cm}$ of cervical dilatation is the transitional phase from the latent phase to the active phase, and progression of labor in the latent phase is generally slow. A previous study interviewed postpartum women concerning their experience during the latent phase and reported that they had experienced difficulty enduring the slow progress and suffering from pain to no avail [27]. In Stage 1-1, the duration in the high JW-DEQ group was significantly longer than that in the low JW-DEQ group $(P=0.024)$. A previous study reported that primiparae who had a significantly longer (over 13 hours) latent phase felt severe 
fear of childbirth immediately after vaginal delivery and caesarean section [28]. The primiparae in our study had vaginal delivery with a normal duration (30 hours or less). Therefore, our results revealed that slow progression of Stage 1-1 and a large overall pain burden experienced during Stage 1-1 could cause fear of childbirth immediately after delivery in primiparae with normal labor progress. We concluded that the overall pain burden reflecting the duration of pain experience, rather than pain intensity at a certain point, should be considered when retrospectively evaluating fear of childbirth after delivery.

Eight primiparae with severe fear of childbirth showed $3.8(S D=0.8)$ hours of Stage 1-2, which was not significantly shorter than those of the low JW-DEQ group $(P=0.052)$, but we considered that the lack of significance could be explained by the limited statistical power. Of eight primiparae with severe fear, six received oxytocin administration to induce or augment the labor. A previous study reported that primiparae who experienced slow labor and received augmented labor perceived severe pain [29]. We considered that a large accumulated labor pain intensity during Stage 1-1 and rapid progress of Stage 1-2 caused by oxytocin administration might increase fear of childbirth immediately after delivery.

Our study had three limitations. First, we did not examine fear of childbirth by using the JW-DEQ version A. Among Japanese primiparae, fear of childbirth during pregnancy is associated with fear of childbirth immediately after birth [13]. We need to conduct a follow-up study from pregnancy to the postpartum period. Second, we could not always evaluate the labor pain intensity in real time, so we used the previous scores instead of a new score or evaluated the labor pain intensity immediately after delivery. Those alternative methods could underestimate the labor pain intensity. We also calculated the AUC assuming that the labor pain intensity at the onset of labor was 0 and increased linearly during Stage 1-1. Women are hospitalized as labor progresses, so it is difficult to measure pain intensity at the time of onset of labor. We need to improve the data collection at the onset of labor. Third, the study used a small number of pregnant Japanese women. The sample was recruited by convenience. We did not calculate a minimum sample size because we could not obtain published data to estimate the difference of fear of childbirth among the high and low JW-DEQ groups as no previous study has evaluated labor pain intensity in real time. Therefore, we cannot generalize the results of correlation between fear of childbirth and labor pain intensity. A selection bias due to the small sample size and recruitment method may have affected our results. We should calculate an appropriate sample size and conduct a further study based on the results of this study.

Fear of childbirth (experience) is an important outcome when considering the quality of midwifery care for women during labor to improve negative birth experiences. Despite our limited knowledge, we emphasize the importance of midwifery care in the latent phase of labor to reduce the fear of childbirth immediately after delivery among pregnant Japanese women who give birth with- 
out obstetrical analgesia or anesthesia during labor. Vaginal delivery is associated with less fear of childbirth after delivery than emergency caesarean section or instrument delivery [15] [30]. However, even in vaginal delivery, the pain experience during labor may give pregnant Japanese women severe fear of childbirth immediately after delivery. In Japan, it is not common to provide pharmacological pain relief. Further studies are needed to provide safer and more comfortable midwifery care to reduce the labor pain intensity and the fear of childbirth related to negative birth experiences.

\section{Conclusion}

We found that a long duration and large amount of accumulated labor pain intensity between the onset of labor and the time of 4 to $6 \mathrm{~cm}$ of cervical dilatation (Stage 1-1) were associated with fear of childbirth immediately after vaginal delivery among Japanese primiparae. It is important that midwives give assistance in the latent phase of labor by focusing on progressing labor smoothly and relieving labor pain to improve negative birth experiences.

\section{Acknowledgements}

This study was supported by Osaka University Graduate School of Medicine and SHISEIKAI Scientific Award.

We would like to thank all the women who consented to participate in this study. We would also like to thank all the doctors and the midwives at Tokyo Women's Medical University Yachiyo Medical Center, Suzuki Clinic and Maeda Clinic in Japan who cooperated to recruit participants to this study.

\section{Conflicts of Interest}

The authors have no conflicts of interest to declare.

\section{References}

[1] Wijma, K., Wijma, B. and Zar, M. (1998) Psychometric Aspects of the W-DEQ; a New Questionnaire for the Measurement of Fear of Childbirth. Journal of Psychosomatic Obstetrics and Gynecology, 19, 84-97. https://doi.org/10.3109/01674829809048501

[2] Saisto, T. and Halmesmaki, E. (2003) Fear of Childbirth: A Neglected Dilemma. Acta Obstetricia et Gynecologica Scandinavica, 82, 201-208. https://doi.org/10.1034/j.1600-0412.2003.00114.x

[3] Takegata, M., Haruna, M., Matsuzaki, M., Shiraishi, M., Okano, T. and Severinsson, E. (2017) Aetiological Relationships between Factors Associated with Postnatal Traumatic Symptoms among Japanese Primiparas and Multiparas: A Longitudinal Study. Midwifery, 44, 14-23. https://doi.org/10.1016/j.midw.2016.10.008

[4] Aksoy, A.N., Ozkan, H. and Gundogdu, G. (2015) Fear of Childbirth in Women with Normal Pregnancy Evolution. Clinical and Experimental Obstetrics \& Gynecology, 42, 179-183.

[5] Storksen, H.T., Garthus-Niegel, S., Adams, S.S., Vangen, S. and Eberhard-Gran, M. (2015) Fear of Childbirth and Elective Caesarean Section: A Population-Based 
Study. BMC Pregnancy and Childbirth, 15, 221.

https://doi.org/10.1186/s12884-015-0655-4

[6] Ryding, E.L., Lukasse, M., Parys, A.-S.V., Wangel, A.-M., Karro, H., Kristjansdottir, H., et al. (2015) Fear of Childbirth and Risk of Cesarean Delivery: A Cohort Study in Six European Countries. Birth, 42, 48-55. https://doi.org/10.1111/birt.12147

[7] Larsson, C., Saltvedt, S., Edman, G., Wiklund, I. and Andolf, E. (2011) Factors Independently Related to a Negative Birth Experience in First-Time Mothers. Sexual \& Reproductive Healthcare, 2, 83-89. https://doi.org/10.1016/j.srhc.2010.11.003

[8] Henriksen, L., Grimsrud, E., Schei, B., Lukasse, M. and Bidens Study, G. (2017) Factors Related to a Negative Birth Experience-A Mixed Methods Study. Midwifery, 51, 33-39. https://doi.org/10.1016/j.midw.2017.05.004

[9] Norvell, K.T., Gastonjohansson, F. and Fridh, G. (1987) Remembrance of Labor Pain: How Valid Are Retrospective Pain Measurements. Pain, 31, 77-86. https://doi.org/10.1016/0304-3959(87)90008-X

[10] Redelmeier, D.A. and Kahneman, D. (1996) Patients' Memories of Painful Medical Treatments: Real-Time and Retrospective Evaluations of Two Minimally Invasive Procedures. Pain, 66, 3-8. https://doi.org/10.1016/0304-3959(96)02994-6

[11] Ministry of Health, Labour and Welfare Vital Statistics. http://www.mhlw.go.jp/english/database/db-hw/populate/dl/01.pdf;2016

[12] Ministry of Health, Labour and Welfare Survey of Medical Institutions. http://www.mhlw.go.jp/toukei/list/dl/130-28_2.pdf;2016

[13] Takegata, M., Haruna, M., Matsuzaki, M., Shiraishi, M., Okano, T. and Severinsson, E. (2015) Does Antenatal Fear of Childbirth Predict Postnatal Fear of Childbirth? A Study of Japanese Women. Open Journal of Nursing, 5, 144-152.

https://doi.org/10.4236/ojn.2015.52017

[14] Takegata, M., Haruna, M., Matsuzaki, M., Shiraishi, M., Murayama, R., Okano, T., et al. (2013) Translation and Validation of the Japanese Version of the Wijma Delivery Expectancy/Experience Questionnaire Version A. Nursing \& Health Sciences, 15, 326-332. https://doi.org/10.1111/nhs.12036

[15] Wiklund, I., Edman, G., Ryding, E.L. and Andolf, E. (2008) Expectation and Experiences of Childbirth in Primiparae with Caesarean Section. BJOG-An International Journal of Obstetrics and Gynaecology, 115, 324-331. https://doi.org/10.1111/j.1471-0528.2007.01564.x

[16] Fenwick, J., Gamble, J., Nathan, E., Bayes, S. and Hauck, Y. (2009) Pre- and Postpartum Levels of Childbirth Fear and the Relationship to Birth Outcomes in a Cohort of Australian Women. Journal of Clinical Nursing, 18, 667-677. https://doi.org/10.1111/j.1365-2702.2008.02568.x

[17] Hjermstad, M.J., Fayers, P.M., Haugen, D.F., Caraceni, A., Hanks, G.W., Loge, J.H., et al. (2011) Studies Comparing Numerical Rating Scales, Verbal Rating Scales, and Visual Analogue Scales for Assessment of Pain Intensity in Adults: A Systematic Literature Review. Journal of Pain and Symptom Management, 41, 1073-1093.

https://doi.org/10.1016/j.jpainsymman.2010.08.016

[18] Hawker, G.A., Mian, S., Kendzerska, T. and French, M. (2011) Measures of Adult Pain Visual Analog Scale for Pain (VAS Pain), Numeric Rating Scale for Pain (NRS Pain), McGill Pain Questionnaire (MPQ), Short-Form McGill Pain Questionnaire (SF-MPQ), Chronic Pain Grade Scale (CPGS), Short Form-36 Bodily Pain Scale (SF-36 BPS), and Measure of Intermittent and Constant Osteoarthritis Pain (ICOAP). Arthritis Care \& Research, 63, S240-S252.

https://doi.org/10.1002/acr.20543 
[19] Jones, L.E., Whitburn, L.Y., Davey, M.-A. and Small, R. (2015) Assessment of Pain Associated with Childbirth: Women's Perspectives, Preferences and Solutions. Midwifery, 31, 708-712. https://doi.org/10.1016/j.midw.2015.03.012

[20] Matthews, J.N.S., Altman, D.G., Campbell, M.J. and Royston, P. (1990) Analysis of Serial Measurements in Medical-Research. British Medical Journal, 300, 230-235. https://doi.org/10.1136/bmj.300.6719.230

[21] Carvalho, B., Hilton, G., Wen, L. and Weiniger, C.F. (2014) Prospective Longitudinal Cohort Questionnaire Assessment of Labouring Women's Preference both Pre- and Post-Delivery for either Reduced Pain Intensity for a Longer Duration or Greater Pain Intensity for a Shorter Duration. British Journal of Anaesthesia, 113, 468-473. https://doi.org/10.1093/bja/aeu149

[22] Logtenberg, S.L.M., Rengerink, K.O., Verhoeven, C.J., Freeman, L.M., van den Akker, E.S.A., Godfried, M.B., et al. (2017) Labour Pain with Remifentanil Patient-Controlled Analgesia versus Epidural Analgesia: A Randomised Equivalence Trial. BJOG-An International Journal of Obstetrics and Gynaecology, 124, 652-660. https://doi.org/10.1111/1471-0528.14181

[23] Nieminen, K., Stephansson, O. and Ryding, E.L. (2009) Women's Fear of Childbirth and Preference for Cesarean Section-A Cross-Sectional Study at Various Stages of Pregnancy in Sweden. Acta Obstetricia et Gynecologica Scandinavica, 88, 807-813. https://doi.org/10.1080/00016340902998436

[24] Haines, H.M., Pallant, J.F., Fenwick, J., Gamble, J., Creedy, D.K., Toohill, J., et al. (2015) Identifying Women Who Are Afraid of Giving Birth: A Comparison of the Fear of Birth Scale with the WDEQ-A in a Large Australian Cohort. Sexual \& Reproductive Healthcare, 6, 204-210. https://doi.org/10.1016/j.srhc.2015.05.002

[25] Alehagen, S., Wijma, B. and Wijma, K. (2006) Fear of Childbirth before, during, and after Childbirth. Acta Obstetricia et Gynecologica Scandinavica, 85, 56-62. https://doi.org/10.1080/00016340500334844

[26] Tzeng, Y.L., Yang, Y.L., Kuo, P.C., Lin, Y.C. and Chen, S.L. (2017) Pain, Anxiety, and Fatigue During Labor: A Prospective, Repeated Measures Study. Journal of Nursing Research, 25, 59-66. https://doi.org/10.1097/jnr.0000000000000165

[27] Carlsson, I.M., Hallberg, L.R.M. and Pettersson, K.O. (2009) Swedish Women's Experiences of Seeking Care and Being Admitted during the Latent Phase of Labour: A Grounded Theory Study. Midwifery, 25, 172-180. https://doi.org/10.1016/j.midw.2007.02.003

[28] Ulfsdottir, H., Nissen, E., Ryding, E.L., Lund-Egloff, D. and Wiberg-Itzel, E. (2014) The Association between Labour Variables and Primiparous Women's Experience of Childbirth; a Prospective Cohort Study. BMC Pregnancy and Childbirth, 14, 7. https://doi.org/10.1186/1471-2393-14-208

[29] Kjaergaard, H., Foldgast, A.M. and Dykes, A.-K. (2007) Experiences of Non-Progressive and Augmented Labour among Nulliparous Women: A Qualitative Interview Study in a Grounded Theory Approach. BMC Pregnancy and Childbirth, 7, 15. https://doi.org/10.1186/1471-2393-7-15

[30] Rouhe, H., Salmela-Aro, K., Toivanen, R., Tokola, M., Halmesmaki, E., Ryding, E. L., et al. (2015) Group Psychoeducation with Relaxation for Severe Fear of Childbirth Improves Maternal Adjustment and Childbirth Experience-A Randomised Controlled Trial. Journal of Psychosomatic Obstetrics and Gynecology, 36, 1-9. https://doi.org/10.3109/0167482X.2014.980722 